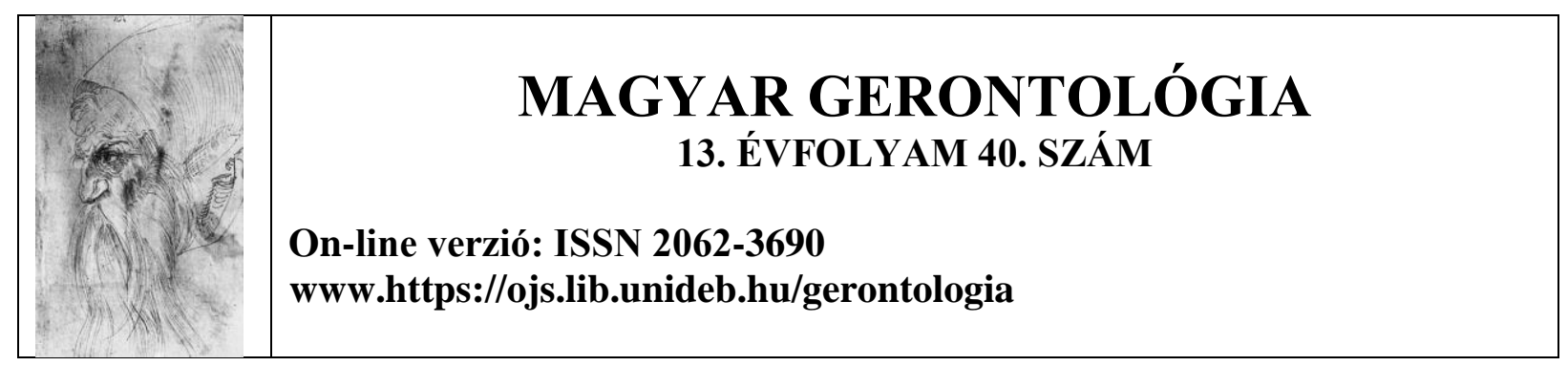

\title{
SENIOR POLICY IN HUNGARY, POLAND, AND RUSSIA Book review
}

\section{Sarah Makar}

ELTE Doctoral School of Social Science

Keywords: senior policy, Central Europe, Hungary, Poland, Russia

\section{Introduction}

By publishing this book authors aimed to provide information about policy measurements on senior populations in Hungary, Poland, and Russia to enable comparisons and identify the best practices.

In addition, the book also includes valuable information relating to the policies on the seniors. The book introduces excessive information about main demographic trends and anticipated changes regarding seniors in Europe in general and more specifically on the above-mentioned countries. Furthermore, the book introduces short analysis of important terms that is used and the progress of these terms in the field. Although retirement policy is unrelated directly to senior policy according to authors, yet it was also covered in the book for its significance in old people's financial and well-being.

About the authors:

Boguslawa Urbaniak - Prof. Ph.D. Habil. Faculty of Economic and Sociology, department of Labour and social policy, Poland.

Yaroslava Evseeva - MA, Russian academy of science, Centre od scientific information studies in social science, Department of Sociology, Russia. 
László Patyán - Ph.D., Faculty of Health, Department of Gerontology, University of Debrecen Hungary.

\section{Chapters and contents}

The book is divided into five chapters; the first, "The European Union is Going Grey," by Boguslawa Urbaniak, highlighted the issue of aging in Europe, where the birth rate is declining, and the number of elderly people is increasing. The chapter discusses the topic of "double aging" in Europe, which means that the number of elderly (+65) and elderly (+80) persons is rapidly increasing, posing a challenge to national social policies in European countries. The chapter provides some extremely useful graphics, such as the percentage of people aged +80 in the EU28 nations in 2018 and the increase in the share of people aged +65 in EU members between 2010 and 2018. The author warns that by the year 2100, the expected rates will have tripled than the rates in 2018. The author's suggestions were that countries should embark on preparing long term action plans to adjust to the main fields of the social policies according to the changes in the demographic structures.

Second chapter of the book "what are we talking about? A terminological analysis" by Boguslawa Urbaniak provides information about different terms related to senior policies. To separate five concepts, the author relied mostly on a study by Syatur-Jaworska (2016); 1. social policy on aging 2 . Social policy on old age 3 . Social policy on elderly people 4 . active aging policy 5. senior policy. The meaning and connotation underlying the terms were included in this chapter, despite the fact that their titles do not reveal any differentiation. Two terms from around the world were mentioned in this chapter: first, "active aging," which refers to the process of maximizing chances for health, involvement, and security in order to improve the quality of life for the elderly. Second, "healthy aging" has reportedly supplanted "active aging" in contemporary documents, according to the author. With the introduction of a department of senior policy by the Ministry of Labour, the author incorporated and defined a country-specific term "senior policy" that has become part of the public discourse in Poland.

Third chapter by László Patyán titled "Senior Policies in Hungary" included a specific analysis of aging policies in Hungary. The chapter begins with a broad set of worldwide aging policies, ranging from age-friendly environments to care policies and universal pension programs. The author briefly summarizes the historical movement in care from institutional to more home-like care, with an emphasis on the well-being and feelings of the elderly. Second, the author highlighted the need of creating an age-friendly environment to not only remove physical 
barriers but also to truly suggest non-discrimination and civic engagement for seniors. Third, the author emphasizes the holistic meaning of "active aging," as well as its significance in the lives of elderly people and certain critics. Finally, the author presented ideal or standard standards for pension policy that promote seniors' rights in his section on social policy guidelines for seniors.

From a broader perspective, the author takes us to Hungary for a more focused look. The unique demographic parameters that influence seniors' social policy in Hungary were illustrated in detail using charts and graphs in this chapter. The author included very serious critics in his fourth section of his chapter about the failures to provide appropriate community services for the elderly due to a variety of reasons, including local government organizational problems, chronic lack of sufficient financial support, a lack of professional knowledge, and a variety of other legislative issues. Positive points, on the other hand, were mentioned, such as the collaboration between local government and non-governmental entities. The importance of church services was also noted favorably. As an example of best practices the author mentioned few examples, those are mainly focuses on the activities of municipalities; one is "Újbuda 60+", and "Nyíregyháza gives more"

Boguslawa Urbaniak's fourth chapter, "Polish Senior Policy," discusses the socioeconomic and political measures that have been implemented in Poland in response to the issues of an aging population. The chapter begins with a summary of senior policy, including examples of initiatives that have been implemented at both the regional and local levels. According to the author, Poland's social policy challenges originate mostly from a lack of clarity in senior policy activities to adapt to ongoing demographic changes in areas such as healthcare, social assistance, education, and housing. addition to issues like the deliberative ignorance of population aging in the public discourse and citizens' poor understanding of healthy aging. Furthermore, there is a shortage of the skilled workers in geriatric care.

The outline also includes a survey's result showed that decision makers and government officials believe that senior care system should be based on family care as the neither the central nor the local authorities can afford to fund the institutionalized care. The outline also named two fundamental documents that direct senior policy in Poland stating very important areas of focus and rights for the wellbeing of the senior citizens. However, there was no mention of how these measures will be implemented or funded, or whether seniors were involved in their formulation. 
Second part of the chapter shortly mentioned some of central and local government's activities such as senior clubs and care in residential nursing center. Further, the author in details gave us a thorough knowledge on policies towards older people in the labor market and retirement policy in Poland supported by graphs and statics. The author explained Poland's pension system how it is managed and funded, how the pension is calculated and what measures the government makes to protect the vulnerable seniors with low income and with disabilities. what are the problems, showed the trail of increasing the age of pension in 2013 and how it was reversed in 2017 and the old age of pension was restored. The chapter also explain the pension for old people with disability in Poland. The author ends her chapter by explaining senior policy in the city and voivodeship (similar to county or governorate in another countries) of Lodz; mentioning the low rates of satisfaction with life and life expectations for men and women in Lodz side by side with the endeavors from the city hall and voivodeship office to work together aiming prevent social exclusion of older people and increase their participation in social, cultural , physical, educational activities and improving their health and wellbeing.

Chapter 5 "Senior policy: Russia and Moscow" gives an overview of the history and contemporary case of social policy towards old people in Russia. The chapter starts short description of demographic information such as life expectancy age, number of pensioners, problem of gender imbalance in the population. Following that, the author takes us in an interesting historical overview to understand the history of care for old people from the $16^{\text {th }}$ century and the role of the church at that time, passing by the soviet era to the contemporary social policy and NGOs' cooperation with the government naming some projects and actively participated in the field NGOs. Proceeding, the Author dedicate the biggest proportion of her chapter to explain the pension system in Russia. Similar to the overview of the senior care, the author mentioned the historical background in the pension system; what is meant to be, how did it develop over years, how was it working in the beginning the soviet union rule and how was it right before the collapse of the system. Furthermore, the author explained the recent pension system and types of pensions and types of pensioners. The author had two important criticism to the new regulations; one with the recent increase of the age of retirement as the healthy ones according to her, will continue working beyond their official retirement. The second with fine or punishment the country stated for business which fire employees before their pension age, as these businesses will try to find a way around it, rather the government should get bounces/ opportunities for developing if they employ or train the older workers. In the forth section, the author stated very important issues regarding the seniors in Labour policy 
showing the statistics about senior who continue to work after the pension and reasons behind it, the attitude towards seniors in the Labour market such as ageism and interviews results of HR specialists' opinion about older employees, rate of hiring old people and the gender representation. The author also puts an alert about the most vulnerable group and the gaps in Labour policy regarding the older employees. The author ends her chapter with the educational cultural policy section towards older people. Mentioning the good practice of the clubs and education center that help seniors to use the internet, learn new languages and have drawing, dace, singing, taking part in sport...etc. in addition to good example of the city Tuymazy, a T.V channel for +50 , people university, leading role Mosco introduce for old people including program "Moskovskoye". The author mentioned studies showing why and why not old people like to learn, and which group is keener in education. The author also named few good examples of associations, centers, NGOs that helps seniors to improve their skills in many activities such as handicraft, ICT, foreign language, photography, community volunteer, nature reserve ...etc.

\section{Strengths}

The authors exerted a sincere effort to explain the senior policy in the three selected counties. The book contains valuable information varying from demographic situation, governmental endeavors in central and community levels to improve the wellbeing of the senior citizen and the good practices and projects. The book is considered reference for scholars who are interested in the field of aging from many aspects, the international law, social policy, gerontology, sociology, public health. The book also considered as a guidance for national decision makers, senior policy makers, local government, and NGOs to solve the problems and fill the gaps in seniors' policy for improving their actively and healthy participation in the society. By introducing a lot of examples for best practices in the three countries, the book delivers valuable information for workers in this field from social workers, care givers, NGOs, centers, and association who deal with seniors. As the three selected countries share the history of being former soviet countries.

The counties share a lot in common; decision maker view towards old citizen, economic burden on the government, former citizen's ideology of dependency on the state to satisfy the needs. Therefore, the comparison between the counties regarding the progress of care for seniors after the collapse of the regime is very practical and functional. 


\section{Critical review}

The book is generally quite useful, but there are a few minor flaws. The large demographic differences across the countries make comparisons difficult; Russia's population alone is 144,500,000, whereas Hungary and Poland have populations of 9,800,000 and 38,000,000, respectively. Another issue is that, as EU states, Hungary and Poland must adhere to EU ideas such as active aging, intergenerational solidarity, age-friendly environments, and aging in place, whereas Russia as a non-Eu country does not have to comply with European Commission's directive and recommendation.

Although the book aimed to enable comparisons between the selected countries, the authors delt with senior policy from one's own understanding and scope of interest. Despite the fact that the authors agree that the pension system is unconnected to senior policy but has a significant impact on the financial and well-being of seniors, it has been explored in depth in the cases of Poland and Russia, but only briefly in the case of Hungary. The section on Russian social policy introduces the historical context of the meaning of social policy and its evolution in Russia, although this historical context was disregarded in Poland and Hungary. The author of the Hungarian social policy chapter was particularly interested in ways to promote the wellbeing and participation of seniors in society, as well as to introduce best practices in the country. While the chapters on the Polish and Russian cases focused more on the legal and economic position of the elderly, they also made a point of addressing regulations and gaps in social policy that significantly influence the lives of the elderly. The same can be said for the "educational and cultural strategy" indicated in the Russian case but not in the Polish or Hungarian cases.

The first chapter even from the title "European union is going grey" excluded the Russian case; many mentioned graphs of course didn't include Russia. The author should be careful about this issue as it affects the coherency of the book.

The second chapter of the book is meant to give analysis of the senior policy by offering definitions and analysis to the terms used in this field. There was no one definition to the "social policy". The author focused one reverence - Syatur Jaworska, (2016)- to differentiate between many types of policies relating to aging, some of the terms did not include in difference in meaning while mentioned in practice it refers to different areas. The author didn't mention whether the usage of these terminology strictly used in Poland or in the international literature as well. Followed by WHO's two terminologies active and healthy aging. More related 
terminology even mentioned in this book where not discussed in this section naming few "aging in place", "age friendly environment", "replacement rate" in calculating pension.

It was unclear what to be considered as policy for senior; Politian's declarations, promises by the government or rearrangements, set of regulations, or strategic plans with time and financial framework.

\section{Recommendation to the authors}

The points of the selected topic should be clearly set and identified before writing; further publications should include the missed parts of the discussion in order to make a feasible comparison between countries.

\section{Conclusion}

The book drives our attention to the fact that the population of old people in Europe is in rapid continues increase, therefore the policy maker should set measurements to adapt to this change. The book contains a lot of valuable information about the demography of old populations, social policy, pension system, cultural policy in Hungary, Poland, and Russia. Authors shed light on the gaps in the social system and problems of old people. On the other hand, the book contains many of best practices and good examples initiatives and programs done by the central and local governments and the civil society as well. All authors introduce recommendations to improve social policy and encourage the good practice for improving seniors' wellbeing, satisfaction, quality of life and healthy and actively engaging in society without discrimination.

\section{Reference}

Urbaniak, B., Evseeva, Y., \& Patyán, L. (2020): Senior Policy in Hungary, Poland and Russia. Wydawnictwo Uniwersytetu Lodzkiego/Lodz University Press.

\section{Author:}

\section{Sarah Makar}

PhD student, ELTE Doctoral School of Social Science Budapest, Hungary. 